\title{
Poly(ADP-ribose) polymerase-1 in high glucose-induced epithelial-mesenchymal transition during peritoneal fibrosis
}

\author{
PING LEI, ZONGPEI JIANG, HENGMEI ZHU, XIAOYAN LI, NING SU and XUEQING YU \\ Department of Nephrology, The First Affiliated Hospital, Sun Yat-Sen University, Guangzhou 510080, P.R. China
}

Received September 25, 2011; Accepted November 4, 2011

DOI: $10.3892 / \mathrm{ijmm} .2011 .859$

\begin{abstract}
Peritoneal fibrosis is a major complication of continuous ambulatory peritoneal dialysis (CAPD). The present study tested the hypothesis that ADP-ribose polymerase-1 (PARP-1) may play a role in peritoneal epithelial-mesenchymal transition and fibrosis under high glucose conditions. High glucose (126 mmol/1)-induced peritoneal EMT and fibrosis via the PARP-1 mechanism was examined in the primary culture of rat peritoneal mesothelial cells (PMCs) and in the human peritoneal mesothelial cell line $(\mathrm{HMrSv} 5)$ in the presence or absence of a PARP-1 inhibitor PJ34 $\left(3 \times 10^{-6} \mathrm{M}\right)$ or by knocking down PARP-1 with the PARP-1 siRNA technique. High glucose significantly increased PARP-1 expression and EMT as demonstrated by de novo expression of a mesenchymal marker $\alpha$-SMA and loss of epithelial phenotype E-cadherin by both rat and human PMC, resulting in peritoneal fibrosis including up-regulation of plasminogen activator inhibitor-1 (PAI-1), collagen I, and fibronectin mRNA and protein expression. All these fibrotic responses induced by high glucose were significantly inhibited by the PARP-1 inhibitor PJ34 (all P<0.05) or by knocking down PARP-1 with the siRNA technique. Results from this study suggested that high glucose stimulates peritoneal EMT and fibrosis via a PARP-1-dependent mechanism, and targeting the PARP-1 may represent an alternative therapeutic potential for CAPD-related peritoneal fibrosis.
\end{abstract}

\section{Introduction}

Peritoneal fibrosis is a severe complication of continuous ambulatory peritoneal dialysis (CAPD), which leads to eventually loss of ultrafiltration and a technical failure of CAPD. It is now clear that EMT is a critical process of peritoneal fibrosis in response to the peritoneal dialysis fluid (PDF) in both patients and animal models. The conventional PDF is a bioincompat-

Correspondence to: Professor Zongpei Jiang, Department of Nephrology, The First Affiliated Hospital Sun Yat-Sen University, 58th Zhongshan Road II, Guangzhou 510080, P.R. China

E-mail: jx.home@medmail.com.cn

Key words: peritoneal mesothelial cells, peritoneal fibrosis, poly(ADP-ribose) polymerase ible solution because of the acidic $\mathrm{pH}$, high concentration of glucose and glucose degradation products (GDP) and lactate (1). These unphysiological compositions may contribute to the development of the peritoneal morphological changes including peritoneal fibrosis. Because high glucose is a very important component in the PDF (2), we therefore examined the influence of high glucose in the process of EMT during peritoneal fibrosis.

Many studies show that high glucose acts by stimulating the protein kinase $\mathrm{C}$ pathway, polyalcohol pathway, AGE pathway and amidohexose pathway to mediate the epithelialmesenchymal transition and extracellular matrix expression. However, blockade of one of these pathways partially inhibits the development of peritoneal fibrosis (3), suggesting that additional mechanisms may participate in the peritoneal fibrosis with long-term PD. We need to find how to simultaneously block these pathways and it may provide an effective therapeutic method to protect the peritoneum from fibrosis.

More and more researchers have found that all kinds of cells injured by high glucose have the same feature which is forming more reactive oxygen species. In the foregoing reports accentuation of oxidative stress and increased ROS were correlated with high glucose. Recently, studies also found increased ROS induced by high glucose may be through inhibition of GAPDH activity to activate protein kinase $\mathrm{C}$ pathway, polyalcohol pathway, AGE pathway and amidohexose pathway, and all of them will inevitably lead to peritoneal fibrosis. But how do ROS inhibit GAPDH activity? Some studies showed that ROS can activate the poly(ADP-ribose) polymerase (PARP) during peritoneal fibrosis (4). PARP is a DNA damage sensor and binds to both single and double stranded DNA to initiate an energy-consuming cycle by transferring $\mathrm{ADP}$ ribose units from $\mathrm{NAD}^{+}$onto nuclear receptor proteins (5). Du et al (6) observed that PARP-specific inhibitors can reverse poly-ADP-ribosylation of GAPDH, and attenuate the inhibition of GAPDH. Other studies $(7,8)$ showed that PARP specific inhibitors can inhibit poly-ADP activation induced by hyperglycemia, suggesting a pathogenic role for PARP in peritoneal fibrosis under high glucose conditions. Thus, the present study tested the hypothesis that high glucose may stimulate the poly-ADP pathway to mediate peritoneal fibrosis in both primary culture of rat PMC and a human PMC line.

\section{Materials and methods}

Chemicals and reagents. D-Glucose was purchased from Shanghai Bio-Engineering Co., Ltd. PJ34 was purchased from 
Table I. Primer sequences of rat genes used for RT-PCR.

\begin{tabular}{|c|c|c|}
\hline Primer & Sequence & Size (bp) \\
\hline Rat $\beta$-actin & $\begin{array}{ll}\text { F } & \text { 5'-GGG AAA TCG TGC GTG ACA TTA-3' } \\
\text { R } & \text { 5'-TCG TCA TAC TCC TGC TTG CTG-3' }\end{array}$ & 475 \\
\hline Rat PARP-1 & $\begin{array}{ll}\mathrm{F} & \text { 5'-ACG CAC AAT GCC TAT GAC-3' } \\
\mathrm{R} & \text { 5'-CAC ATC TCC AAG GCG ACC-3' }\end{array}$ & 441 \\
\hline Rat $\alpha$-SMA & $\begin{array}{ll}\text { F } & \text { 5'-GCT CTG TAA GGC GGG CTT TG-3' } \\
\text { R } & \text { 5'-ACG AAG GAA TAG CCA CGC TCA-3' }\end{array}$ & 558 \\
\hline Rat E-cadherin & $\begin{array}{ll}\text { F } & \text { 5'-CAG GAT TAC AAG TTC CCG CCA-3' } \\
\text { R } & \text { 5'-CAC TGT CCG CTG CCT TCA G-3' }\end{array}$ & 354 \\
\hline Rat PAI-1 & $\begin{array}{ll}\text { F } & \text { 5'-ATG GAA CAA GAA TGA GAT CA-3' } \\
\text { R } & \text { 5'-TCA AAG GGT GCT GCA ATG AAC-3' }\end{array}$ & 471 \\
\hline Rat fibronectin & $\begin{array}{ll}\text { F } & \text { 5'-CTG AAG TCA CTT CTC GGG GTG C-3' } \\
\text { R } & \text { 5'-GCA CAA CAG ACC ACC AAA CTC G-3' }\end{array}$ & 430 \\
\hline
\end{tabular}

Merck Sharp and Dohme Pty, Ltd. (Whitehouse Station, NJ). Ethylenediamine tetraacetic acid (EDTA) and Dulbecco's modified Eagle's medium (DMEM) medium were all from Invitrogen (Carlsbad, CA). ADP-ribose polymerase-1 (PARP-1) siRNA, sense, 5'-GGGCAAGCACAGUGUCAAATT-3' and antisense, 5'-UUUGACACUGUGCUUGCCCTT-3', was synthesized by the Shanghai Zimmar Pharmaceutical Technology Co., Ltd.

Cell culture. Rat primary peritoneal mesothelial cells were isolated as described previously (9). In brief, healthy male Sprague-Dawley rats weighing about $150 \mathrm{~g}$ were anesthetized, and about $20-30 \mathrm{ml}$ of phosphate-buffered saline (PBS) containing $0.25 \%$ trypsin and $0.02 \%$ EDTA was infused into the peritoneal cavity and rinsed for $90 \mathrm{~min}$. Sediments from the recovered fluids were cultured in medium DMEM (Invitrogen) supplemented with $10 \%$ fetal bovine serum. The cultures were passed 2-3 times before experiments. The isolated cells were examined by phase contrast microscopy, electron microscopy and immunohistochemical analysis to confirm its phenotypes. The animal experiments were approved by the Ethics Committee of Animal Research of Sun Yat-Sen University and performed in accordance with the NIH's Guide for the Care and Use of Laboratory Animals.

Experimental conditions. Peritoneal mesothelial cells were cultured in DMEM containing 10\% fetal bovine serum. Arrested rat peritoneal mesothelial cells (RPMCs) were stimulated by $1.36 \%$ glucose for $0,12,24,48$ and $72 \mathrm{~h}$ to detect the PARP-1 mRNA expression. The PARP-1 mRNA expression was detected at $24 \mathrm{~h}$ in RPMCs induced by $1.36,2.27$ and $3.86 \%$ glucose. Subconfluent mesothelial cells were incubated with serum-free media for $24 \mathrm{~h}$ to arrest and synchronize the cell growth. Some cells were treated with fresh serum-free DMEM containing D-glucose $(2.27 \%)$. Some cells were treated with D-glucose $(2.27 \%)$ and the PARP-1 inhibitor PJ34 $\left(3 \times 10^{-6} \mathrm{M}\right)$ or PARP-1 siRNA $\left(5 \times 10^{-8} \mathrm{M}\right)$. These cells were harvested at $24 \mathrm{~h}$ for analysis.

PARP-1 siRNA for transient transfection. Subconfluent human peritoneal mesothelial cells were cultured in 6-well plates and transfected with siRNAs at a final concentration of $50 \mathrm{nM}$ in $1000 \mathrm{ml}$ DMEM, using Lipofetamine 2000 as the transfection reagent. After incubation for $4 \mathrm{~h}$ at $37^{\circ} \mathrm{C}, 2.5 \mathrm{ml} /$ well complete DMEM was added and cells were allowed to grow for the times indicated. In cell growth experiments, silenced cells were harvested by trypsinization, seeded in 6-well plates and transfected again using exactly the conditions described above. In this way, several rounds of subculturing, transfection and growth were repeated on the same cell stocks. Cells were collected at $24 \mathrm{~h}$ after transfection to determine PARP-1 protein and mRNA levels.

Reverse transcription-polymerase chain reaction (RT-PCR). The mRNA levels of PARP-1 and E-cadherin, $\alpha$-SMA, plasminogen activator inhibitor-1 (PAI-1), FN were assessed by RT-PCR. Total-RNA from PMCs was extracted using TRIzol reagent, and converted into cDNA with the MBI RevertAid ${ }^{\mathrm{TM}}$ First Strand cDNA synthesis system according to the manufacturer's manual. Subsequently, the polymerase reaction was performed using the MBI system (all from Invitrogen). The forward and reverse primers used in this study are shown in Tables I and II. The amplification was performed with the following cycles: $94^{\circ} \mathrm{C} 5 \mathrm{~min}, 94^{\circ} \mathrm{C} 30 \mathrm{sec}, 53^{\circ} \mathrm{C} 30 \mathrm{sec}, 72^{\circ} \mathrm{C}$ $45 \mathrm{sec}$ and $72^{\circ} \mathrm{C} 10 \mathrm{~min}$ (the annealing temperature varied with different primers). Each sample was tested in triplicate. To confirm the amplification specification, the PCR products were subject to agarose gel electrophoresis. The result was normalized by $\beta$-actin and expressed as relative changes to control.

Western blot analysis. The protein levels of PARP-1, $\alpha$-SMA, E-cadherin, PAI-1, vimentin and collagen-1 protein expression were examined by Western blot analyses. At the end of the incubation, cells were washed with PBS and lysed in $150 \mu \mathrm{l}$ of lysis buffer containing protease inhibitors for $5 \mathrm{~min}$ on ice. Conditioned media and cell lysates were centrifuged at $5,000 \times \mathrm{g}$ at $4^{\circ} \mathrm{C}$ for $15 \mathrm{~min}$, and the concentrations of the cellular protein were determined using Bio-Rad assay (Bio-Rad Laboratories, Hercules, CA). Samples with equal 
Table II. Primer sequences of human genes for RT-PCR.

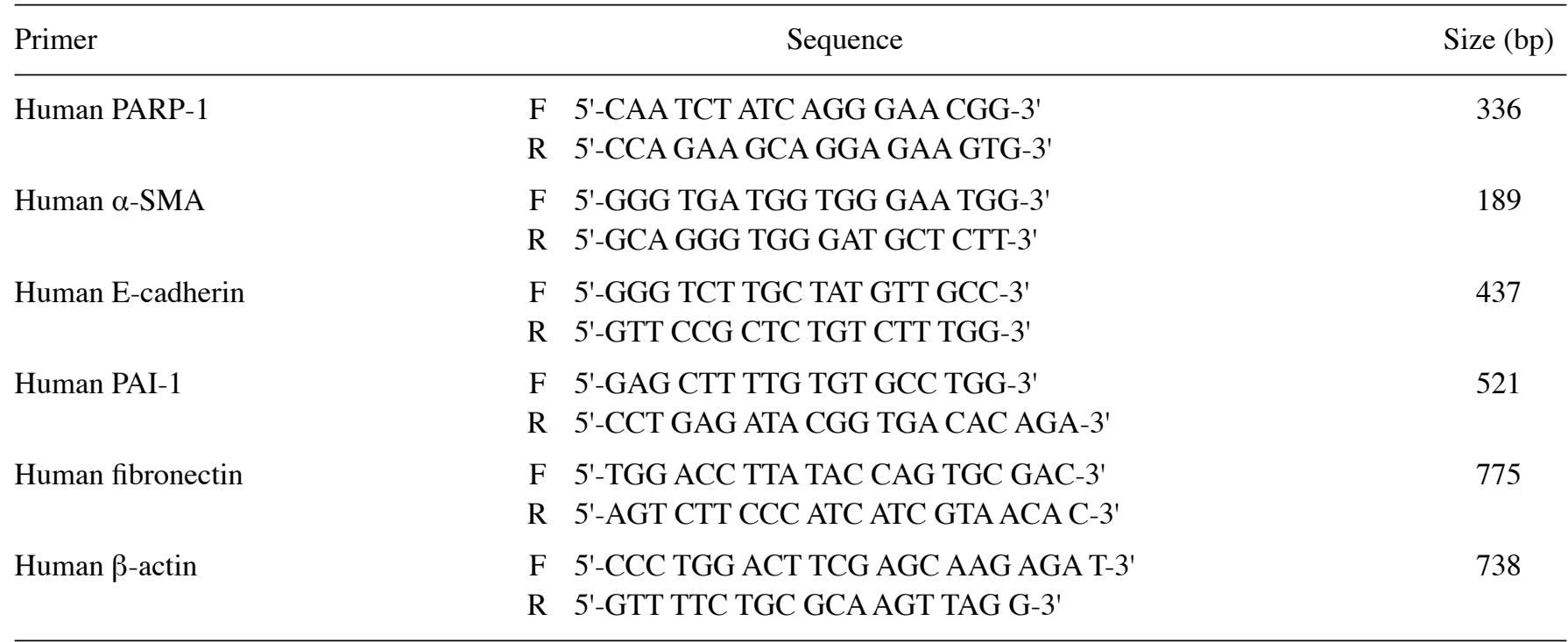

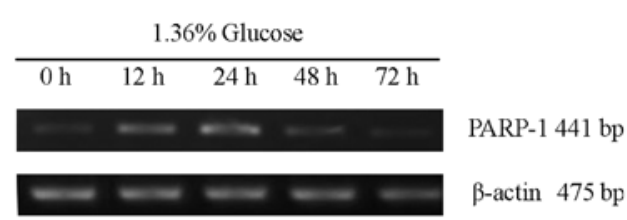

B

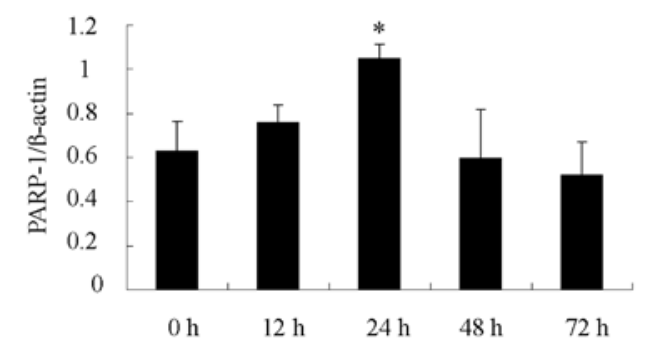

Figure 1. High (1.36\%) glucose induced PARP-1 mRNA expression in rat PMCs were measured by RT-PCR. Values are expressed as mean \pm SEM of three independent experiments. $\mathrm{P}<0.05$ vs. 0 h group.

concentrations of cellular protein $(30 \mu \mathrm{g})$ were mixed with a 5X sample buffer and heated at $95^{\circ} \mathrm{C}$ for $10 \mathrm{~min}$ and separated on $10 \%$ SDS-polyacrylamide gels. After electrophoresis for $90 \mathrm{~min}$, the proteins were transferred onto a nitrocellulose membrane using a transblot chamber with Tris buffer $(0.025 \mathrm{M}$ Tris- $\mathrm{HCl}, 0.192 \mathrm{M}$ glycine and $20 \% \mathrm{MeOH})$. The membranes were blocked for $1 \mathrm{~h}$ at room temperature with $5 \%$ nonfat milk in TBS-Tween-20. Membranes were incubated at $4^{\circ} \mathrm{C}$ overnight with a dilution of antibody of $\alpha$-SMA (Dako, Denmark), PAI-1 (Santa Cruz Biotechnology Inc., Santa Cruz, CA, USA), PARP-1, E-cadherin, vimentin or collagen-1. After extensive washing in TBS-Tween-20, the membranes were incubated with peroxidase-conjugated secondary anti-mouse IgG or anti-rabbit IgG (Cell Signaling Technology Inc., Danvers, MA, USA) for $1 \mathrm{~h}$ at room temperature. After washing, the membranes were incubated with an enhanced chemiluminescence system (ECL) detection kit. Positive immunoreactive bands were quantified densitometrically, normalized by $\beta$-actin and compared with controls.

Statistical analysis. All results were expressed as mean $\pm \mathrm{SE}$ with $n$ as the number of experiments. Analysis of variance (ANOVA) was used to assess the differences between multiple groups using the SPSS 11.0 software (SPSS Inc., Chicago, IL). A value of $\mathrm{P}<0.05$ was used as the criterion for a statistically significant difference.

\section{Results}

Characterization of cultured rat PMCs. The confluent RPMCs showed a uniform cobblestone-like appearance under the phase contrast microscope. Immunohistochemical studies revealed a positive staining for cytokeratin and vimentin, but a negative staining for Factor VIII and CD45 (data not shown).

Expression of PARP-1 in RPMCs induced by high glucose $(1.36 \%)$. High glucose (1.36\%) significantly up-regulated PARP-1 mRNA expression in a time-dependent manner up to $24 \mathrm{~h}$ compared with the $0 \mathrm{~h}$ group (Fig. 1) $(\mathrm{P}<0.05)$. It also increased PARP-1 mRNA expression. Specifically, $2.27 \%$ glucose (Fig. 2) significantly increased the PARP-1 mRNA expression by 2.20 -fold compared with the control group $(\mathrm{P}<0.05)$.

High glucose is able to up-regulate PARP-1 expression in primary cultures of rat and human PMCs. High (2.27\%) glucose significantly increased the PARP-1 mRNA expression by 2.20 -fold compared with the control group in rat PMCs $(\mathrm{P}<0.05)$. PJ34 effectively inhibited the high glucose-induced PARP-1 mRNA expression by $45.0 \%(\mathrm{P}<0.05)$ compared with the high glucose group (2.27\%) (Fig. 3). Accordingly, the PARP-1 protein expression in rat PMCs was also up-regulated by 1.97 -fold compared with control group $(\mathrm{P}<0.05)$. PJ34 effectively inhibited the high glucose-induced PARP-1 protein expression by $51.1 \%(\mathrm{P}<0.05)$ compared with the high glucose group (2.27\%) (Fig. 4). The mRNA and protein expression of 
A

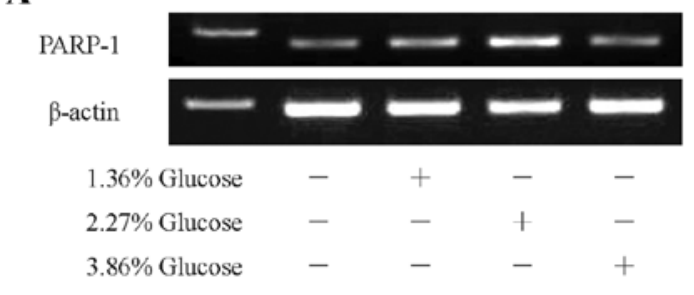

B

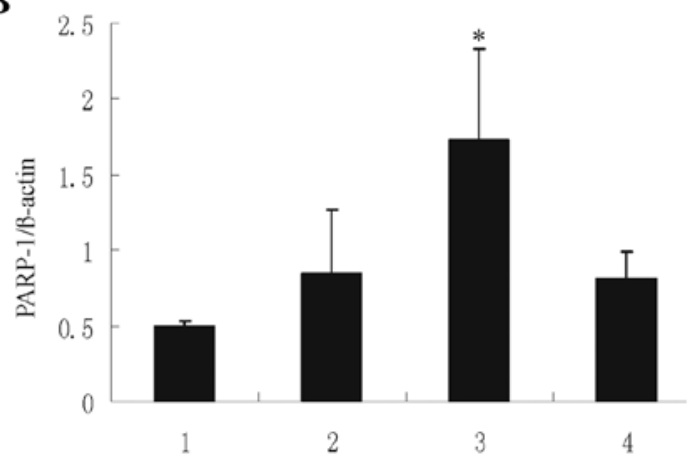

Figure 2. High glucose-induced PARP-1 mRNA expression in rat PMCs were measured by RT-PCR. Values are expressed as mean \pm SEM of three independent experiments. 1 , control group; $2,1.36 \%$ glucose group; $3,2.27 \%$ glucose group; $4,3.86 \%$ glucose group; ${ }^{\mathrm{P}}<0.05$ vs. the control group.

A

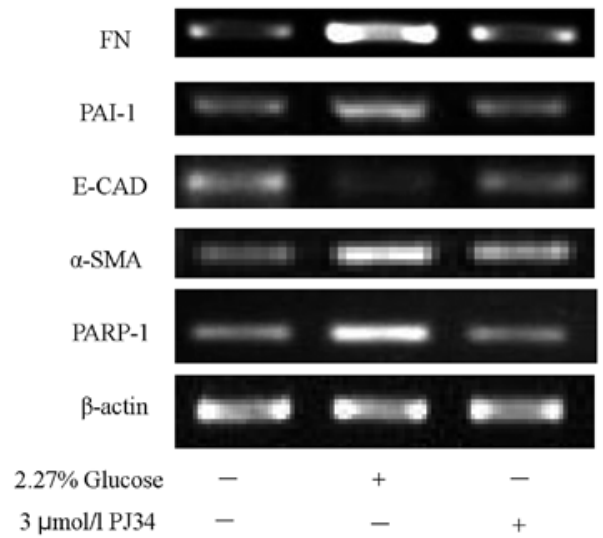

B

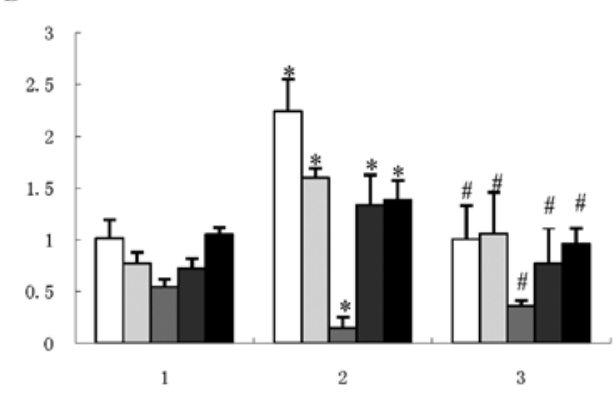

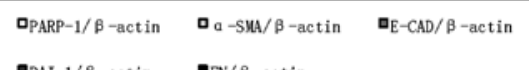

$$
\begin{aligned}
& \text { - } \mathrm{PAI}-1 / \beta \text {-actin } \quad \text { FN/ } \beta \text {-actin }
\end{aligned}
$$

Figure 3. Effect of the PARP-1 inhibitor PJ34 $\left(3 \times 10^{-6} \mathrm{M}\right)$ on high glucoseinduced mRNA overexpression of PARP-1, $\alpha$-SMA, E-cadherin (E-CAD), PAI-1, fibronectin (FN) in rat PMCs. Values are expressed as mean \pm SEM of three independent experiments. 1, control group; 2, 2.27\% glucose group; 3 , $2.27 \%$ glucose $+\mathrm{PJ} 34\left(3 \times 10^{-6} \mathrm{M}\right)$ group. ${ }^{*} \mathrm{P}<0.05$ vs. the control group; ${ }^{~} \mathrm{P}<0.05$ vs. the $2.27 \%$ glucose group.

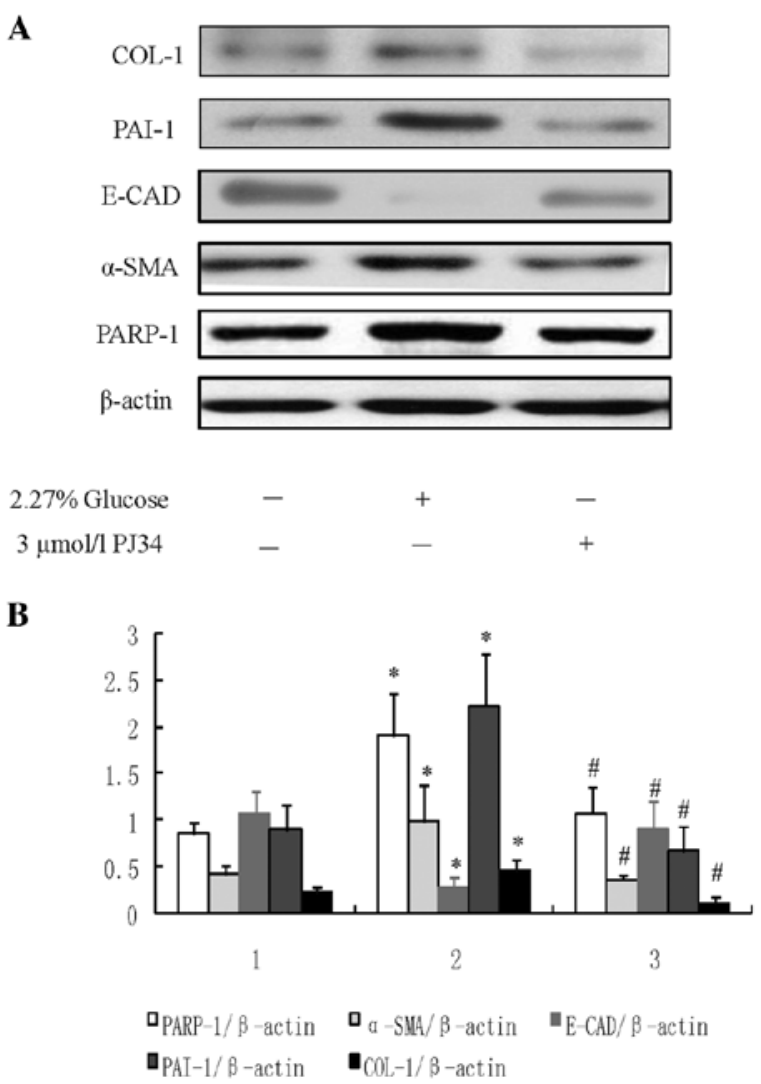

Figure 4. Effect of PARP-1 inhibitor PJ34 $\left(3 \times 10^{-6} \mathrm{M}\right)$ on high glucose-induced protein overexpression of PARP-1, $\alpha$-SMA, E-cadherin (E-CAD), PAI-1, collagen-1 (COL-1) in rat PMCs. The protein expression was measured by Western blot analysis. Values are expressed as mean \pm SEM of three independent experiments. 1, control group; 2, 2.27\% glucose group; 3, 2.27\% glucose $+\mathrm{PJ} 34\left(3 \times 10^{-6} \mathrm{M}\right)$ group. ${ }^{*} \mathrm{P}<0.05$ vs. the control group; ${ }^{\text {}} \mathrm{P}<0.05$ vs. the $2.27 \%$ glucose group.

PARP-1 in human PMCs were significantly up-regulated by high glucose (2.27\%) (Figs. 5 and 6). Compared with control group, the mRNA expression of PARP-1 was up-regulated by 1.67 -fold $(\mathrm{P}<0.05)$. Protein expression was up-regulated by 1.46 -fold $(\mathrm{P}<0.05)$ (Fig. 6). PARP-1 siRNA significantly inhibited the up-regulation of PARP-1 expression induced by high glucose. Compared with high glucose stimulation group, the inhibition rate of PARP-1 mRNA expression was 34.3\% $(\mathrm{P}<0.05)$, and the inhibition rate of their protein expression was $33.3 \%(\mathrm{P}<0.05)$.

High glucose-induced EMT in primary cultures of rat and human PMCs is mediated by PARP-1. High glucose $(2.27 \%)$ stimulated $\alpha$-SMA mRNA overexpression in rat PMCs by 2.06-fold $(\mathrm{P}<0.05)$ compared with control group. PJ34 effectively down-regulated high glucose induced $\alpha$-SMA mRNA overexpression by $33.8 \%(\mathrm{P}<0.05)$ (Fig. 3). Accordingly, the $\alpha$-SMA protein expression in rat PMCs was also up-regulated by 2.37 -fold compared with control group $(\mathrm{P}<0.05)$. PJ34 effectively inhibited high glucose-induced $\alpha$-SMA protein expression by $62.6 \%(\mathrm{P}<0.05)$ (Fig. 4). High glucose decreased E-cadherin mRNA expression in rat PMCs by $27.6 \%$ compared with the control group. High glucose-induced down-regulation of E-cadherin mRNA expression was effectively prevented by treatment with PJ34 [40\% (P<0.05)] (Fig. 3). Also, the 
A

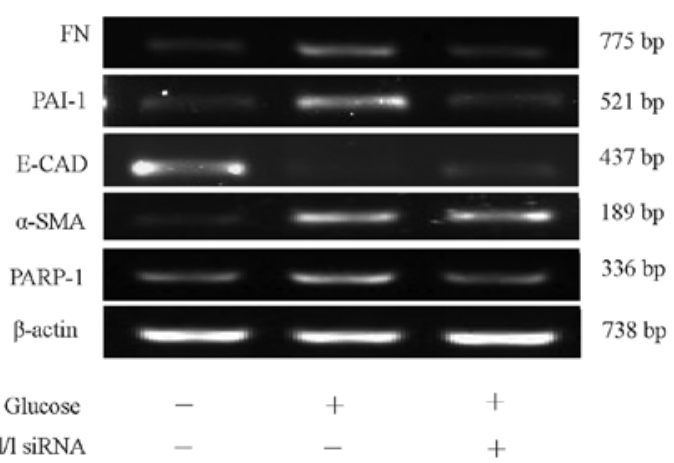

B

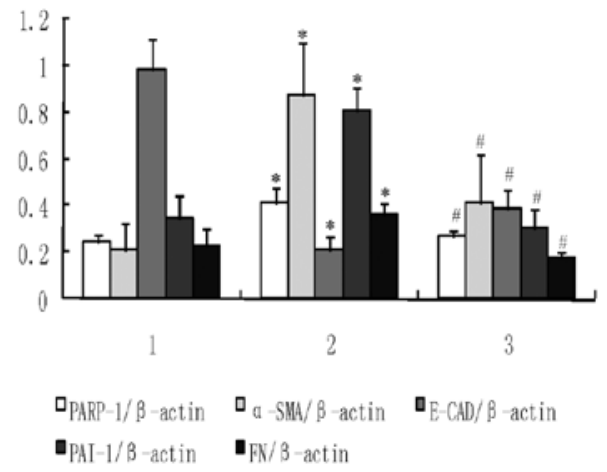

Figure 5. Effect of PARP-1 siRNA $\left(5 \times 10^{-8} \mathrm{M}\right)$ on high glucose induced mRNA overexpression of PARP-1, $\alpha$-SMA, E-cadherin (E-CAD), PAI-1, fibronectin (FN) in human PMCs. The mRNA expression was measured by RT-PCR. Values are expressed as mean \pm SEM of three independent experiments. 1, control group; 2, 2.27\% glucose group; 3, 2.27\% glucose + PARP-1 siRNA $\left(5 \times 10^{-8} \mathrm{M}\right)$ group. ${ }^{*} \mathrm{P}<0.05$ vs. control group; ${ }^{\#} \mathrm{P}<0.05$ vs. $2.27 \%$ glucose group.

E-cadherin protein expression was down-regulated by high glucose by $25.2 \%$ in rat PMCs $(\mathrm{P}<0.05)$. PJ34 effectively reversed high glucose-induced E-cadherin protein downregulation by $137 \%(\mathrm{P}<0.05)$ compared with the $2.27 \%$ high glucose group (Fig. 4). The mRNA and protein expression of $\alpha$-SMA in human PMCs were significantly up-regulated by $2.27 \%$ glucose. Compared with the control group, the mRNA expression of $\alpha$-SMA (Fig. 5) was up-regulated by 4.2 -fold $(\mathrm{P}<0.05)$. Protein expression was up-regulated by 1.57 -fold $(\mathrm{P}<0.05)$ (Fig. 6). PARP-1 siRNA significantly inhibited the up-regulation of $\alpha$-SMA expression in human PMCs induced by high glucose. Compared with the high glucose stimulation group, the inhibition rate of $\alpha$-SMA mRNA expression was $52.8 \%(\mathrm{P}<0.05)$, and the inhibition rate of their protein expression was $30.6 \%(\mathrm{P}<0.05)$. Also, high glucose significantly down-regulated the expression of E-cadherin, compared with the control group. The mRNA (Fig. 5) and protein (Fig. 6) expression was down-regulated by 78.2 and $25.7 \%$, respectively $(\mathrm{P}<0.05)$. PARP-1 siRNA effectively reversed high glucose-induced E-cadherin mRNA and protein expression by 81.0 and $37.0 \%$, respectively $(\mathrm{P}<0.05)$.

Functional importance of PARP-1 in the high glucose-induced peritoneal PAI- 1 and extracellular matrix expression in the primary culture of rat and human PMCs. High glucose significantly up-regulated PAI-1 mRNA expression by 1.85 -fold in rat PMCs compared with the control group $(\mathrm{P}<0.05)$ (Fig. 3). Also,
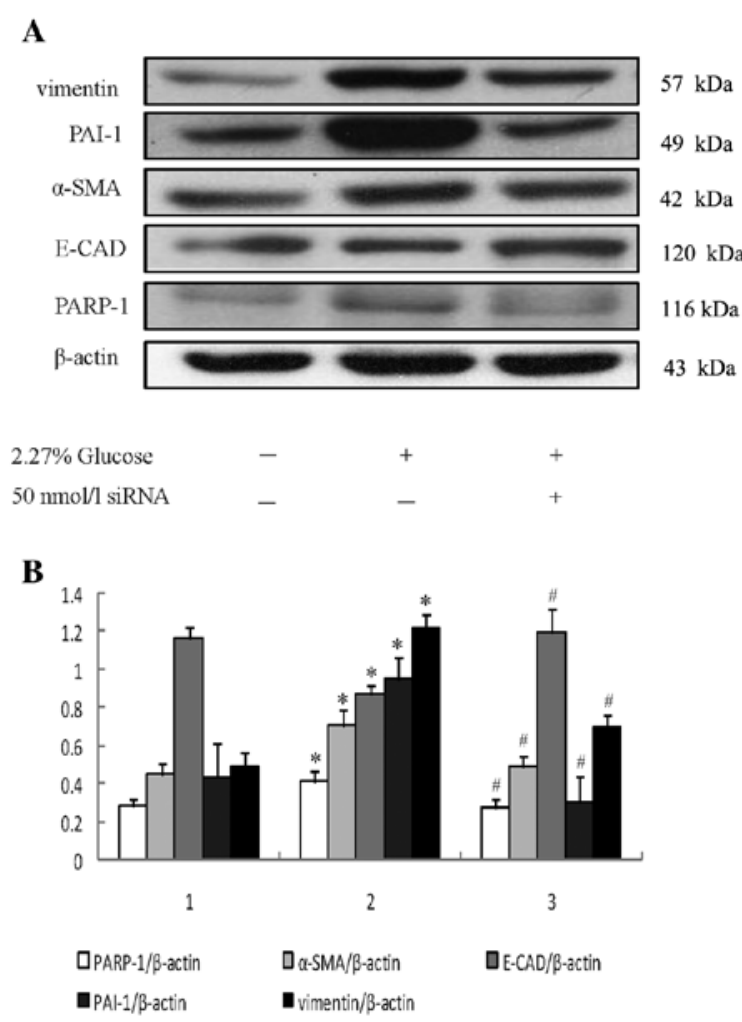

Figure 6. Effect of PARP-1 siRNA $\left(5 \times 10^{-8} \mathrm{M}\right)$ on high glucose induced protein overexpression of PARP-1, $\alpha$-SMA, E-cadherin (E-CAD), PAI-1, vimentin in human PMCs. The protein expression was measured by Western blot analysis. Values are expressed as mean \pm SEM of three independent experiments. 1, control group; 2, 2.27\% glucose group; 3, 2.27\% glucose + PARP-1 siRNA $\left(5 \times 10^{-8} \mathrm{M}\right)$ group. ${ }^{*} \mathrm{P}<0.05$ vs. control group; ${ }^{\#} \mathrm{P}<0.05$ vs. $2.27 \%$ glucose group.

in rat PMCs high glucose up-regulated the fibronectin mRNA expression by 1.32 -fold $(\mathrm{P}<0.05)$ (Fig. 3). PAI-1 [2.48-fold $(\mathrm{P}<0.05)]$ (Fig. 4) and collagen-1 [2.06-fold $(\mathrm{P}<0.05)]$ protein expression in rat PMCs were also up-regulated by high glucose at $24 \mathrm{~h}$ after stimulation. High glucose-induced PAI-1 mRNA overexpression was significantly down-regulated by $42.2 \%$ with $\mathrm{PJ} 34(\mathrm{P}<0.05)$ whereas its protein overexpression was down-regulated by $69.7 \%(\mathrm{P}<0.05)$. Collagen-1 protein overexpression was also down-regulated by $75.7 \%(\mathrm{P}<0.05)$ with PJ34. Treatment with PJ34 effectively down-regulated high glucose induced FN mRNA overexpression by $30.7 \%$ $(\mathrm{P}<0.05)$.

The mRNA and protein expression of PAI-1 were significantly up-regulated by high glucose in human PMCs (2.27\%) (Figs. 5 and 6). Compared with the control group, the mRNA expression of PAI-1 was up-regulated by 2.32 -fold $(\mathrm{P}<0.05)$. Their protein expression was up-regulated by 2.19 -fold $(\mathrm{P}<0.05)$ (Fig. 6). PARP-1 siRNA significantly inhibited the up-regulation of PAI-1 expression induced by high glucose. Compared with the high glucose stimulation group, the inhibition rate of PAI-1 mRNA expression was $62.1 \%(\mathrm{P}<0.05)$, and the inhibition rate of their protein expression was $68.3 \%(\mathrm{P}<0.05)$. High glucose up-regulated fibronectin mRNA expression in human PMCs by 1.61 -fold $(\mathrm{P}<0.05)$. Treatment with PARP-1 siRNA effectively down-regulated high glucose-induced FN mRNA overexpression by $50.9 \%(\mathrm{P}<0.05)$. Vimentin protein expression in human PMCs were up-regulated by high glucose at 
$24 \mathrm{~h}$ after stimulation by 2.49 -fold $(\mathrm{P}<0.05)$. Vimentin protein overexpression was also down-regulated by $42.3 \%(\mathrm{P}<0.05)$ with PARP-1 siRNA.

\section{Discussion}

The PARP enzyme family has at least six members, including PARP-1, PARP-2, PARP-3, PARP-4/PVP ARP, Tankyrase-1, Tankyrase-2. PARP-1 is the first and most important member in the family (10). PARP-1 is a 116-kDa protein that consists of three main domains: the N-terminal DNA-binding domain containing two zinc fingers, the automodification domain, and the C-terminal catalytic domain.

Over-activation of PARP by reactive oxygen and nitrogen intermediates represents a pathogenetic factor in various forms of inflammation, myocardial reperfusion injury, heart transplantation, heart failure, stroke, circulatory shock, and autoimmune $\beta$-cell destruction associated with diabetes mellitus (11-14). Activation of PARP and the beneficial effect of various PARP inhibitors have been demonstrated in various forms of endothelial dysfunction, such as those associated with circulatory shock, hypertension, atherosclerosis, pre-eclampsia, and aging $(15,16)$. Unfortunately, there are no reports about the role of PARP in the pathogenesis of peritoneal fibrosis.

Our data demonstrated that peritoneal mesothelial cells incubated with high glucose stimulation underwent a transition from an epithelial phenotype to a mesenchymal phenotype, with the up-regulation of $\alpha$-SMA and down-regulation of E-cadherin expression, at both the mRNA and protein levels. These findings have been previously reported (17). PJ34 is a newly developed selective PARP-1 inhibitor based on a modified phenanthridinone structure and is 10,000 times more potent than the prototypical PARP inhibitors nicotinamide and 3-aminobenzamide (18). PJ34, unlike earlier generation PARP inhibitors, has no antioxidant properties and acts by competitive blockade of the $\mathrm{NAD}^{+}$binding site in the enzyme. We found that treatment with PJ34 inhibited not only PARP-1 expression but also EMT induced by high glucose in PMCs. This finding implied that PARP may be a critical component in the formation of EMT. High glucose increased both PAI-1 mRNA and protein expression, and collagen-1 protein expression and fibronectin mRNA expression in RPMCs. These observations confirmed that high glucose might be a major contributor in regulating the accumulation of ECM in rat peritoneal mesothelial cells. Kim et al (19) also reported that high glucose can induce ECM and eventually peritoneal fibrosis. Our data demonstrated that, treatment with PJ34 not only inhibited PARP-1 expression but also significantly downregulated the expression of PAI-1, collagen-1 and fibronectin. These observations imply that PARP-1 may play an important role in high glucose-induced ECM.

PARP activation depletes the intracellular concentration of its substrate $\mathrm{NAD}^{+}$, slowing the rate of glycolysis, electron transport, and ATP formation, and produces an ADP-ribosylation of the GAPDH inhibiting GAPDH activity. It leads to a glucose metabolism shift from glycolysis to other biosynthetic pathways (8). High glucose through binding of advanced glycation end products (AGE) to their receptor (RAGE) increases the expression of TGF- $\beta$ and contributes to the development of peritoneal fibrosis. Anti-RAGE antibodies have prevented the up-regulation of TGF- $\beta$, development of fibronectin accumulation, and peritoneal fibrosis (20). High glucose decreases collagenase expression and increases TIMP mRNA and protein expression in cultured human peritoneal mesothelial cells. These changes in collagenase and TIMP expression induced by high glucose were abrogated upon pretreatment with the PKC inhibitor (19). High glucose-induced activation of diacylglycerol PKC (DAG-PKC) plays a major role in the up-regulation of MCP-1, TGF- $\beta 1$, and fibronectin synthesis by HPMC cultured under high glucose (21).

It has also been proven that VEGF-siRNA could inhibit VEGF expression (22). It can inhibit the angiogenesis of endothelial cells in vitro and the tumor growth and lengthen the survival of lung cancer cells in vivo. Recent advances (23) regarding the utility of RNA interference (RNAi) to specifically inhibit HIV-1 replication have opened new possibilities for the development of gene-based therapies against HIV-1 infection. Suckau et al (24) reported on targeted RNAi for the treatment of heart failure. Cohausz et al (25) found that PARP-1 siRNA could down-regulated PARP-1 protein expression, it was confirmed by immunofluorescence. Our data indicate that high glucose up-regulated PARP-1 mRNA and protein expression in HPMCs, and PARP-1 siRNA may partly inhibit PARP-1 expession. In the meanwhile high glucose could induce human peritoneal mesothelial cell transdifferentiation and the accumulation of ECM, PARP-1 siRNA effectively inhibited the process of EMT and ECM in human peritoneal mesothelial cells, suggesting that PARP-1 mediates high glucose-induced EMT and the accumulation of ECM in HPMCs.

In conclusion, we demonstrated that PARP-1 expression in peritoneal mesothelial cells and high glucose induced the expression of PARP-1 in peritoneal mesothelial cells. Moreover, high glucose induced EMT and the accumulation of ECM in peritoneal mesothelial cells, which can be resolved by PJ34 and PARP-1 siRNA. Treatment to aim directly at PARP-1 may be a new target of protecting the peritoneum from fibrosis.

\section{Acknowledgements}

This study was supported by a grant from the National Natural Science Foundation of China (no. 30771012).

\section{References}

1. Ha H, Cha MK, Choi HN and Lee HB: Effects of peritoneal dialysis solutions on the secretion of growth factors and extracellular matrix proteins by human peritoneal mesothelial cells. Perit Dial Int 22: 171-177, 2002.

2. Witowski J, Korybalska K, Ksiazek K, et al: Peritoneal dialysis with solutions low in glucose degradation products is associated with improved biocompatibility profile towards peritoneal mesothelial cells. Nephrol Dial Transplant 19: 917-924, 2004.

3. Brownlee M: Biochemistry and molecular cell biology of diabetic complications. Nature 414: 813-820, 2001.

4. De Vriese AS: The John F. Maher recipient lecture 2004: rage in the peritoneum. Perit Dial Int 25: 8-11, 2005.

5. Cookson MR, Ince PG, Usher PA and Shaw PJ: Poly(ADP-ribose) polymerase is found in both the nucleus and cytoplasm of human CNS neurons. Brain Res 834: 182-185, 1999.

6. Du X, Matsumura T, Edelstein D, et al: Inhibition of GAPDH activity by poly(ADP-ribose) polymerase activates three major pathways of hyperglycemic damage in endothelial cells. J Clin Invest 112: 1049-1057, 2003. 
7. Kiss $\mathrm{L}$ and Szabo C: The pathogenesis of diabetic complications: the role of DNA injury and poly(ADP-ribose) polymerase activation in peroxynitrite-mediated cytotoxicity. Mem Inst Oswaldo Cruz 100 (Suppl 1): S29-S37, 2005.

8. Okada H,Inoue T, Kikuta T, et al: Poly(ADP-ribose) polymerase-1 enhances transcription of the profibrotic CCN2 gene. J Am Soc Nephrol 19: 933-942, 2008.

9. Akiba T, Ota T, Fushimi K, et al: Water channel AQP-1 in the primary cell culture of rat peritoneum. Adv Perit Dial 15: 3-6, 1999.

10. Gradwohl G, Menissier de Murcia JM, Molinete M, et al: The second zinc-finger domain of poly(ADP-ribose) polymerase determines specificity for single-stranded breaks in DNA. Proc Natl Acad Sci USA 87: 2990-2994, 1990.

11. Zingarelli B, Salzman AL and Szabo C: Genetic disruption of poly (ADP-ribose) synthetase inhibits the expression of P-selectin and intercellular adhesion molecule-1 in myocardial ischemia/ reperfusion injury. Circ Res 83: 85-94, 1998.

12. Szabo G, Bahrle S, Stumpf N, et al: Poly(ADP-ribose) polymerase inhibition reduces reperfusion injury after heart transplantation. Circ Res 90: 100-106, 2002.

13. Pacher P, Liaudet L, Bai P, et al: Activation of poly(ADP-ribose) polymerase contributes to development of doxorubicin-induced heart failure. J Pharmacol Exp Ther 300: 862-867, 2002.

14. Jagtap P, Soriano FG, Virag L, et al: Novel phenanthridinone inhibitors of poly (adenosine 5'-diphosphate-ribose) synthetase: potent cytoprotective and antishock agents. Crit Care Med 30 1071-1082, 2002.

15. Hung TH, Skepper JN, Charnock-Jones DS and Burton GJ: Hypoxia-reoxygenation: a potent inducer of apoptotic changes in the human placenta and possible etiological factor in preeclampsia. Circ Res 90: 1274-1281, 2002.

16. Martinet W, Knaapen MW, De Meyer GR, Herman AG and Kockx MM: Elevated levels of oxidative DNA damage and DNA repair enzymes in human atherosclerotic plaques. Circulation 106: 927-932, 2002.
17. Lai KN, Tang SC and Leung JC: Mediators of inflammation and fibrosis. Perit Dial Int 27 (Suppl 2): S65-S71, 2007.

18. Suarez-Pinzon WL, Mabley JG, Power R, Szabo C and Rabinovitch A: Poly(ADP-ribose) polymerase inhibition prevents spontaneous and recurrent autoimmune diabetes in NOD mice by inducing apoptosis of islet-infiltrating leukocytes. Diabetes 52: $1683-1688,2003$

19. Kim JJ, Li JJ, Kim KS, et al: High glucose decreases collagenase expression and increases TIMP expression in cultured human peritoneal mesothelial cells. Nephrol Dial Transplant 23: 534-541, 2008.

20. De Vriese AS, Flyvbjerg A, Mortier S, Tilton RG and Lameire NH: Inhibition of the interaction of AGE-RAGE prevents hyperglycemia-induced fibrosis of the peritoneal membrane. J Am Soc Nephrol 14: 2109-2118, 2003

21. Yao Q, Qian JQ, Lin XH and Lindholm B: Inhibition of the effect of high glucose on the expression of Smad in human peritoneal mesothelial cells. Int J Artif Organs 27: 828-834, 2004.

22. Zhang Y, Gu ZP, Zhou YA and Wang YJ: Effect of inhabitation of VEGF expression with RNA interference on lung cancer therapy. Xi Bao Yu Fen Zi Mian Yi Xue Za Zhi 25: 341-347, 2009 (In Chinese).

23. Martinez MA: Progress in the therapeutic applications of siRNAs against HIV-1. Methods Mol Biol 487: 343-368, 2009.

24. Suckau L, Fechner H, Chemaly E, et al: Long-term cardiactargeted RNA interference for the treatment of heart failure restores cardiac function and reduces pathological hypertrophy. Circulation 119: 1241-1252, 2009.

25. Cohausz O, Blenn C, Malanga M and Althaus FR: The roles of poly(ADP-ribose)-metabolizing enzymes in alkylation-induced cell death. Cell Mol Life Sci 65: 644-655, 2008. 